Der folgende Text wird über DuEPublico, den Dokumenten- und Publikationsserver der Universität Duisburg-Essen zur Verfügung gestellt.

Diese Version der E-Publikation ist kein Verlagsangebot und kann von einer eventuell ebenfalls veröffentlichten Verlagsversion abweichen.

Oades, Robert D.; Zerbin, Dieter; Dittmann-Balcar, Alexandra:

The topography of event-related potentials in passive and active conditions of a 3-tone auditory oddball test

http://duepublico.uni-duisburg-essen.de/servlets/DocumentServlet?id=25489

Quelle: In: International Journal of Neuroscience, 81 (1995) ; 1-2, p. 249 - 264 / doi:10.3109/00207459509004890 


\title{
THE TOPOGRAPHY OF EVENT-RELATED POTENTIALS IN PASSIVE AND ACTIVE CONDITIONS OF A 3-TONE AUDITORY ODDBALL TEST
}

\author{
R. D. OADES, D. ZERBIN and A. DITTMANN-BALCAR \\ RLHK Clinic for Child and Adolescent Psychiatry, Pf 103043 , \\ D-45030 Essen, Germany.
}

\begin{abstract}
Nornalized event-related potential (ERP) data were analysed for topographical differences of ERP amplitude or latency in two conditions of a 3-tone oddball paradigm. The aim was to compare perception-related features relating to tone-type (passive non-task condition) with focussed attention-related features (active discrimination of target from non-target) in 5 ERP components from 23 young healthy subjects. The tones used were a common standard $(70 \%, 0.8 \mathrm{KHz})$, a deviant standard $(15 \%, 2 \mathrm{KHz})$ and a $1.4 \mathrm{KHz}$ tone $(15 \%, \mathrm{t})$ also used as the target (T). A site $x$ tone interaction was obtained for Pl amplitude (augmenting with pitch anterior to posterior). The opposite tendency was seen for P2 to the right of midline maxima. No interaction was obtained for N1 amplitude. Condition became relevant for the N2-P3 complex. Frontal N2 amplitude increased after rare tones in the active condition. Posterior P3 peak size distinguished between tone (more widespread response to the common tone) and condition (more right-sided in the passive condition). The common tone elicited more widespread shift to the right than the rare tones. Latency was affected by condition from the P2 onwards and contirmed many of the amplitude interactions. This report extends and qualifies well-known main effects of tone and condition through main site effects to lateral sites. It supports claims of multiple sources of ERP components, except for N1 and P2. The contributions of these sources are influenced by tone-features (from P1) and the presence or absence of focussed attention (from the N2-P3 complex).
\end{abstract}

Keywords: event-related potentials, topography, $P I, N I, P 2, N 2, P 3$, attention

The use of event-related potentials (ERP) in psychiatry has been hindered by the lack of specificity of changes of particular measures (e.g., amplitude, latency) to diagnosis and uncertainty over the interpretation of the mental process represented by each component (see discussions on P3 amplitude in schizophrenia and other psychiatric diagnoses (Ford et al., 1992); P3 latency in aging and dementia (Polich, 1991a) and on putative attentional and memory trace roles for early negative (Näätänen, 1990) and later positive peaks (Verleger, 1988, Donchin \& Coles, 1988)).

The aim of the present study was 1) to show the differential influence of stimulus variables of pitch and presentation-frequency (perception-related processing during diffuse attention) on a range of ERP components in a 3-tone oddball paradigm, 2) to compare these results during the passive condition with differences recorded during an active discrimination between the same stimuli to demonstrate the influence of focussed attention, and 3) to show how the attentional effects are distributed topographically. (With regard to the psychological intervening variables, this article emphasizes the role of focussed vs diffuse at- 
tention and the accompanying article the type of stimulus matching process required in information processing, as reflected by selected subtraction waves).

Increasing precision of experimental design has advanced our understanding of the conditions modulating ERPs in healthy subjects but two technical developments of the last decade stand out as potentially fruitful in the field of psychiatry. The one is the capability of subtracting two waveforms elicited by events whose difference is well-known and the other is source localization. The former is discussed in the second of these two reports.

Source localization methods follow three separate directions, - the measurement of magnetic fields, dipole calculation and scalp topography. While each method varies in precision and the nature of the information provided, only the latter is both technically within the grasp of most clinical laboratories and easily applicable in useful test paradigms with subjects sensitive to stress (cf. questions of cost or the number of trials necessary).

Therefore topographic data are presented from healthy young subjects bearing on two questions basic to and potentially useful for the study of psychiatric patients. The two or three tone oddball discrimination provides a useful paradigm for patients in that the stimulus parameters are among those likely to be affected by psychiatric disability, namely tonepitch, presentation-frequency, wakefulness vs focussed attention and stimulus and task relevance.

Previous comparisons of passive/active responses have concentrated on the P3 component in the 2-tone oddball and been limited to 3 midline recording sites. They showed that the N1/P2/N2/P3 components were recognizeable in the passive waveform and followed generally the better known waveform in active conditions (Polich, 1987), that latencies may reflect age, dementia and independently measured psychometric performance (O'Donnell et al., 1990; Tachibana et al., 1992) but P3 latencies at Fz can be shorter or longer than at $\mathrm{Pz}$ (Tachibana et al. vs Polich).

Our study extended the number of recording sites and used the less usual 3-tone paradigm to avoid confounding pitch or rarity with task-relevance and passive and active (discrimination) conditions to test for the effect of focussed attention over diffuse attention (see 2-stimulus oddball critique in Breton et al., 1988). Studies with 3 auditory stimuli have shown that ERP amplitude may decrease and latency increase with the increased level of difficulty and distractibility introduced, but again they concentrated on the P3 component at midline sites (Pfefferbaum et al., 1984; Grillon et al., 1990). However large early negative responses to rare standards have been reported (Oades et al., 1988, Novak et al., 1990; Rugg et al., 1993). These latter studies have concentrated on specific components in subtraction waves (see accompanying article) rather than the role of focussed attention itself.

The question of topography requires an analysis of normalized data to avoid confusion of the additive nature of statistical models with the multiplicative features of the CNS (McCarthy \& Wood, 1985). Does the ERP topography differ according to tone pitch/probability, and according to diffuse/focussed attention? Most studies have been restricted to the N2/P3 complex and whether normalized data show different distributious between sensory modalities (Naumann et al., 1992) or between two diagnostic groups (O'Donnell et al., 1993). The results were, respectively, negative and positive.

While it seems inherently more likely that there could be different topographical regions manifesting peak activity to stimuli in different modalities, it remains necessary to show whether this possibility could apply to different stimuli in the same modality. A reductionist argument would suggest that if resolution were fine enough there would be a difference. For the auditory $\mathrm{N} 1$ there is already evidence of tonotopic pitch separation in the auditory cortex (Näätänen et al., 1988; Scherg et al., 1989). With regard to the possibility of topo- 
graphic changes reflecting a change from diffuse to focussed attention there is evidence for different anatomical loci for the sources of $\mathrm{Nl}$ and subtraction-waves around the $\mathrm{N} 1 \mathrm{la}$ tency (Teder et al., 1993) and the differential dependence of P3 amplitude on stimulus attributes parietally and frontally (Squires et al., 1975) and on temporal asymmetry (Curran et al., 1993). Indeed there is some evidence for multiple generators for most ERP components studied so far (see discussion).

In summary this report provides a profile of potential perceptual and attentional influences in a 3-tone oddball on the amplitude and latency of 5 ERP components (P1-P3), briefly considering the effects of condition and tone at $\mathrm{Cz}$ and principally considering the topographical main effect of recording site and its interaction with tone and condition. (A significant interaction is necessary for inferring separate anatomical sources for a component, Johnson, 1993).

\section{METHODS}

\section{Subjects}

Recordings were analysed from 23 physically and mentally healthy subjects who reported no history of neurological disorder and who claimed to be free of medication (details see Table 1). They were volunteers paid for performing a psychological test battery.

\section{Procedure}

All recordings were made between 09:30 and 11.00 between August and December (mostly in October). A 3-tone auditory oddball paradigm was presented in successive passive (diffuse attention) and active (focussed attention) discrimination sessions. Blocks of a hundred $0.8,1.4$ and $2.0 \mathrm{KHz}$ tones ( $65 \mathrm{dBSL})$ were presented in a Bernoulli sequence $(p=70,15$ and $15 \%$ respectively). The tones had a rise and fall time of $10 \mathrm{~ms}$, a duration of $50 \mathrm{~ms}$ with an interval of 1.2-1.7 sec between the start of each stimulus.

Tones were generated by a gate-function-generator (Exact) and played through DT 48 earphones (Bayer Dynamics). Hearing thresholds were measured with an Audio-Med audiometer BCA3 immediately before recording. Mean left/right thresholds were 20.3/20.4 $(0.8 \mathrm{KHz}), 16.8 / 16.7(1.4 \mathrm{KHz})$ and $10.8 / 11.9 \mathrm{~dB}(2 \mathrm{KHz})$. Where left-right thresholds varied by more than $5 \mathrm{~dB}$ sound levels were adjusted accordingly. The number of such cases per tone was $6(0.8 \mathrm{KHz}), 5(1.4 \mathrm{KHz})$ and $10(2 \mathrm{KHz}): 7$ persons showed a mild relative impairment on the left and 7 on the right.

\section{TABLE 1}

Subject characteristics, recording data accepted and reaction time

\begin{tabular}{|c|c|c|c|c|c|c|c|c|c|c|}
\hline \multirow[b]{2}{*}{$\begin{array}{l}\text { Male/ } \\
\text { female }\end{array}$} & \multirow[b]{2}{*}{$\begin{array}{c}\text { Age }(y) \\
\text { mean }\end{array}$} & \multirow[b]{2}{*}{$\begin{array}{c}\text { SPM IQ } \\
\text { (mean) }\end{array}$} & \multirow[b]{2}{*}{$\begin{array}{c}\text { MMPI } \\
\text { 3Ns }\end{array}$} & \multirow[b]{2}{*}{$\begin{array}{c}\text { (mean) } \\
4-9\end{array}$} & \multirow[b]{2}{*}{$2-7-8$} & \multirow[b]{2}{*}{$\begin{array}{c}\text { Artifact } \\
\%\end{array}$} & \multicolumn{4}{|c|}{ Active condition } \\
\hline & & & & & & & $\begin{array}{c}0.8 \\
\mathrm{KHz}\end{array}$ & $\begin{array}{c}\text { accept } \\
2.0 \\
\mathrm{KHz}\end{array}$ & $\begin{array}{c}1.4 \\
\mathrm{KHz}\end{array}$ & $\mathrm{RT}$ \\
\hline $\begin{array}{ll}7 \quad 16\end{array}$ & 21.9 & 122.3 & 48.1 & 51.1 & 46.9 & 20 & 187 & 34 & 31 & 552 \\
\hline$s d$ & 1.7 & 12.2 & 4.7 & 5.4 & 5.1 & 11 & 51 & 8 & 6 & 94 \\
\hline
\end{tabular}

\% artifact: elimination of ujals due to electrical arifact in passive and active conditions: accepted recordings and reaction time concern the aclive condition after removal of EOG artifact and response errors: 0.8 .2 .0 and $1.4 \mathrm{KHz}$ tones were respectively the common tone, the deviant strandard and the target: MMPI $3 \mathrm{Ns}=$ neurotic scales of depression, hypochondria and hysteria; $4-9=$ psychopathic deviance kcales; $2-7-8=5 c h i z o t y p a l$ scales: $\mathrm{SPM}=$ Raver's standard progressive matrices measure of performance $1 \mathrm{Q}$. RT = reaction time. 
Recordings were made in a sound-attenuated, air-conditioned, electrically-isolated room $(3.8 \times 2.7 \times 3.0 \mathrm{~m})$ illuminated by a $25 \mathrm{w}$ bulb. Subjects sat in a reclining soft chair $1.5 \mathrm{~m}$ from a small cross on the wall, which they were asked to fixate during the recording to reduce eye-movements. Subjects were told there would be a baseline recording over $2-3$ trialblocks before the second part where they would have to respond to one of the tones. At the end of the passive session most subjects had identified 3 tones which were then demonstrated. Only in the active discrimination session were they informed which stimulus was the target. Response involved raising the finger from a metal contact as fast but as correctly as possible after the $1.4 \mathrm{KHz}$ tone.

Recordings were made from 19 sites in an electrocap (10:20 system) using linked ear reference and $\mathrm{Fpz}$ and $\mathrm{Oz}$ as separate ground electrodes, with an impedance of $<2 \mathrm{KOhm}$ at all sites. ERPs were evaluated at 15 sites, -F7, F3, Fz, F4, F8; C3, Cz, C4; P3, Pz, P4; T3, T4, T5, T6). From these data and that from two Fp and two $\mathrm{O}$ sites $(5 \times 5$ grid), topographic maps were made using a horizontal and vertical linear interpolation (Crout algorhythm) to establish a matrix of $180 \times 180$ points.

Data were recorded on a Siemens EEG 21 and $20 \mathrm{MHz}$ Compaq $386 \mathrm{pc}$, sampled at 250 $\mathrm{Hz}$ for $1024 \mathrm{~ms}$ (including $50 \mathrm{~ms}$ pretrigger time) and amplified by $12 \mathrm{~K}$ using a band pass 0.3 to $70 \mathrm{~Hz}$ (analog Butterworth filter). Recordings with EOG artifact $>65 \mathrm{uV}$, recorded above the eye, were eliminated (table 1). This with the setting of low pass filters reduced gross EMG interference. Data were evaluated offline using a digital, low-pass, rectangular $25 \mathrm{~Hz}$ filter to reduce noise in the assessment of small peaks. These parameters satisfy recommendations for recording cognitive ERPs (Polich, 1991b). Problems of aliassing and delays in the topographic sampling of latencies are reduced by the sampling rate and the normalization of the latency data for statistical purposes, respectively (Pivik et al., 1993).

\section{ERP Definitions}

Waveforms were evaluated after the common standard $(0.8 \mathrm{KHz})$, the deviant $(2.0 \mathrm{KHz})$ and the $1.4 \mathrm{KHz}$ target tone (passive $=\mathrm{t}$, active $=\mathrm{T}$ ). $\mathrm{P} 1$ was the largest positive-going dip preceding the N1 (30-100 ms). As such it does not necessarily represent the P1 or P50 of other authors. N1 was the earliest large negative-going wave $80-140 \mathrm{~ms}$ post-stimulus. P2 was the largest positive-going post-N1 wave preceding N2 (120-240 ms). N2 was the largest negative peak after P2 and before P3 (140-300 ms). The P3 component was the largest post-P2 positive-going waveform between 240 and $540 \mathrm{~ms}$.

\section{Data Analysis}

Data were normalized using the vector analysis method (McCarthy \& Wood, 1985) separately for each tone and condition ( 6 data sets) in order to test for the potential independent effect of each tone and each condition, as has been carried out in the comparison of ERPs elicited by visual and auditory stimuli (Naumann et al., 1992). Thus the mean value of the measure at each site for each subject was divided by a vector obtained by taking the square root of the sum of the squared mean measures obtained for each of the 15 sites studied. "Vector normalization" has the advantage a) vs raw data, of correcting for inhomogeneous data, b) for analyses of variance, of correcting for the multiplicative effect on ERPs of changes of source strength, c) vs percentage and min-max normalization methods, of taking account of the variance at all recording sites evaluated.

A 3-way MANOVA for 2 conditions (passive/active), 3 tones and 15 electrode sites with repeated measures was conducted for each component measure (e.g., Keselman \& Rogan, 
1980; Iragui et al., 1993), With the study's aim centred on the topography of individual component measures and the influence of condition (attention) and tone-type on topography main site effects and site interactions with condition and tone were analysed. A multivariate analysis was employed with electrode-site treated as a within-subjects factor as a precaution against between subject variability. Significant results are reported after a) Hotelling's T2 test as an assessment of potential between-measure differences (Faux \& McCarley, 1990) and b) SPSSX "averaged" tests for 15 sites after correction with the appropriate epsilon (e) factor (Greenhouse \& Geisser, 1959; Vasey \& Thayer, 1987, see appendix).

Significant results in both tests were followed by post-hoc tests to determine where the difference lay. Significant main effects (e.g., site) were followed by selected paired Student $\mathrm{t}$-tests for the analysis of dependent variables, namely 6 comparisons between anterior/posterior (F7/T5, Fz/Pz, F8/T6) and left/right lateral sites (F7/8, T3/4, T5/T6). Paired comparisons were selected to guard against performing an excessive number of comparisons; nonetheless alpha was corrected according to the Bonferroni procedure (e.g., $1 \%$ for comparisons after main site effects with no interactions, $0.5 / 0.2 \%$ for condition/tone comparisons and $0.1 \%$ after 3-way interactions). Significant interactions (with 2 or 3 independent variables; i.e., condition and tone) were followed by one-way ANOVA or conservative Scheffe tests as appropriate at $5 \%$ and $1 \%$ levels and are cited in the text. Clearly insignificant interactions $(p>0.1)$ are not reported.

In the text the terms "tendency, trend and tend" refer to a statistical significance of 5-10\% or where Hotellings and averaged tests gave contradictory evidence of significance. Interpretation of the interactions was set in the context of the main effects obtained with 2way ANOVA for condition and tone at $\mathrm{Cz}$ performed on the raw data. The analysis at $\mathrm{Cz}$ is briefly described first in the sections on each component (first main effect then interactions, if any, see table 2). The main effect of site (normalized data) is followed by t-tests and interactions with tone and condition by Scheffe tests.

\section{RESULTS}

\section{PI}

Amplitude. At $\mathrm{Cz}$ larger responses to targets (10-25\%) dominated the main tone effect $(\mathrm{F}(2,132)=5.2, p=.007)$. There was no effect of condition.

Larger responses over anterior than posterior sites were seen only after the $0.8 \mathrm{KHz}$ tone ( $\mathrm{t}=+4.3, p=.000$ ). All tones (particularly the deviant) produced larger responses on the right $(50-300 \%)$ at posterior sites $(t-2.3$ to $-3.6, p<.02-0.003$; Fig. 1$)$.

Tone but not condition interacted with site. There was an "augmenting" pattern with the $0.8 \mathrm{KHz}$ producing smaller and $2.0 \mathrm{KHz}$ larger responses at posterior sites (e.g., T6, Scheffe $p<.05)$.

Latency. Latencies were shorter at anterior than posterior sites in both hemispheres $(13-32 \%: t=-3.1$ to $-9.3, p<.003$ ) but more so on the left (by $5-15 \%$; see Fig. 2 and Table 2).

\section{NI}

Amplitude. There were no effects of tone or condition at any site. Larger amplitudes recorded at all frontal sites decreased posteriorly by $60-70 \%(\mathrm{t}=-20.5$ to $-23.6, p=.000$; 


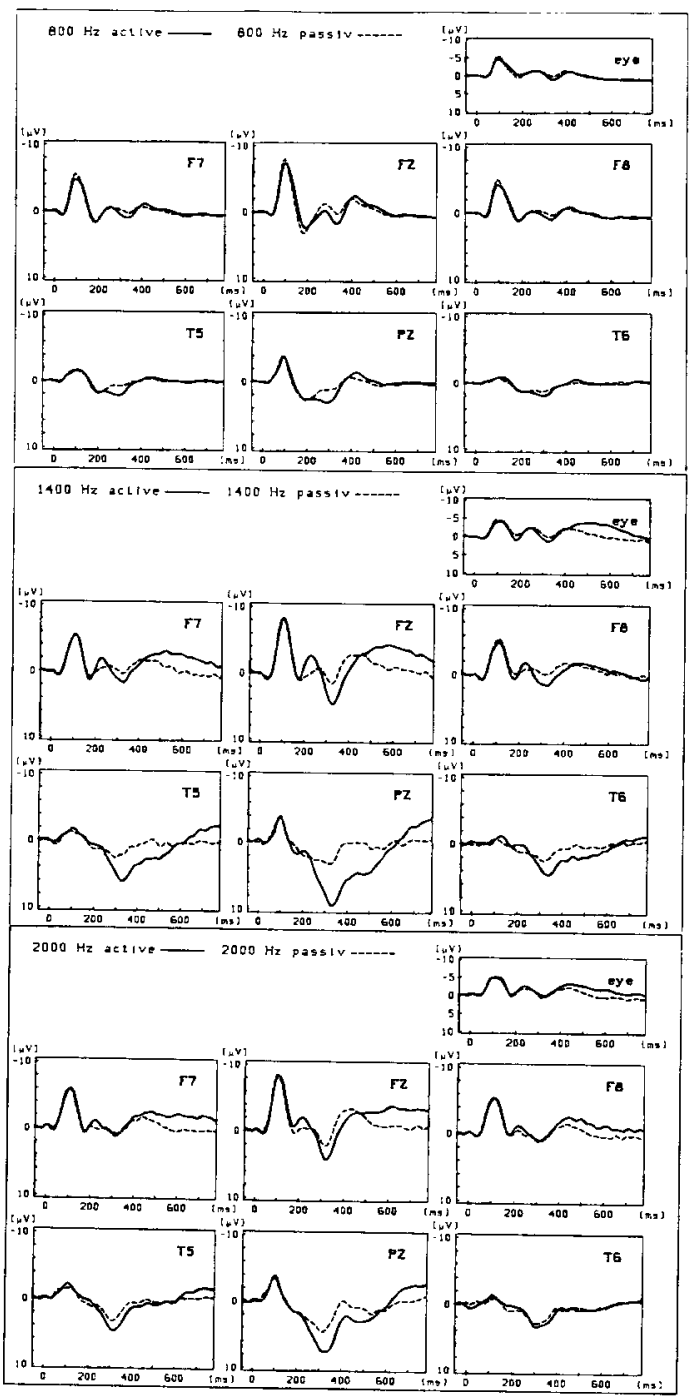

FIGURE 1 Grand mean ERP waveforms (uv) after 0.8 (common), 2.0 (deviant) and $1.4 \mathrm{KHz}$ tones (t/T) in passive and active conditions over $800 \mathrm{~ms}$ post-stimulus. 


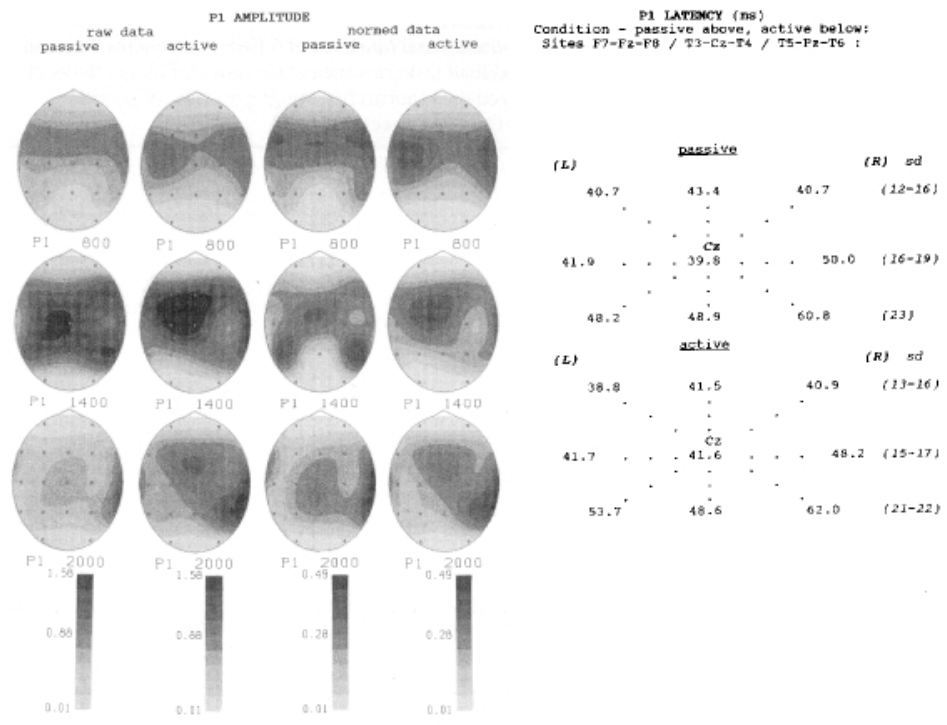

FIGURE 2 (Left) Topographic distribution of raw data and vector-normalized peak amplitudes (uv) after 3 tones $(0.8,1.4$ and $2.0 \mathrm{KHz})$ in passive/active conditions where anterior sites are uppermost in each map. Raw $\mathrm{PI}$ amplitudes were largest at $\mathrm{Cz}$ after $\mathrm{t}$ and $\mathrm{T}$; normalized data show 1) the main localized vertex response, 2) the augmenting sequence over the right side-anterior (common), medial ( $\mathrm{T}$ ) and posterior (deviant), especially in the active condition. (Right) Topographic representation of latencies (ms) from selected sites after $\mathrm{t}(1.4 \mathrm{KHz}$. passive condition) and $\mathrm{T}(1.4 \mathrm{KHz}$ target in active condition) with standard deviation range on the right. Shorter latencies occurred anteriorly and over the left hemisphere.

Fig. 3). At anterior and posterior sites peaks were larger on the left (by $8-27 \%$, respectively, $\mathrm{t}=-5.0$ to $-6.7, p=.000$ ).

Latency. $\quad \mathrm{N} 1$ peaked $5-8 \%$ earlier at lateral frontal vs posterior sites $(\mathrm{t}=-2.9$ to $-4.3, p$ $=.000-.004)$ and $5 \%$ earlier on the left $(\mathrm{t}=-5.0, p<.000)$. There were no anteroposterior differences in the midline.

P2

Amplitude. At $\mathrm{Cz}$ peaks tended to show a "reducing" effect with respect to pitch (Table 2) that was not supported after normalization (Fig. 4).

P2 peaks were larger posteriorly (by $20 \%, \mathrm{Pz}$ vs Fz, T6 vs F8 ( $\mathrm{t}=-3.3$ to $-3.9, p=.000)$ and at frontal sites they were larger on the left $(\mathrm{t}=5.4, p=.000)$. The borderline tone-site interaction was not significant after e-correction) and was not confirmed post-hoc.

Latency. At $\mathrm{Cz}$ there was a trend for shorter latencies in the active condition $(\mathrm{F}(2,132)=$ $2.8, p=.067$, Fig. 4, Table 2). P2 for all tones peaked earlier at left vs right frontal sites $(\mathrm{c} .3 \%), \mathrm{t}=-3.7, p<.000$ ) but significant interactions with site were not confirmed. 

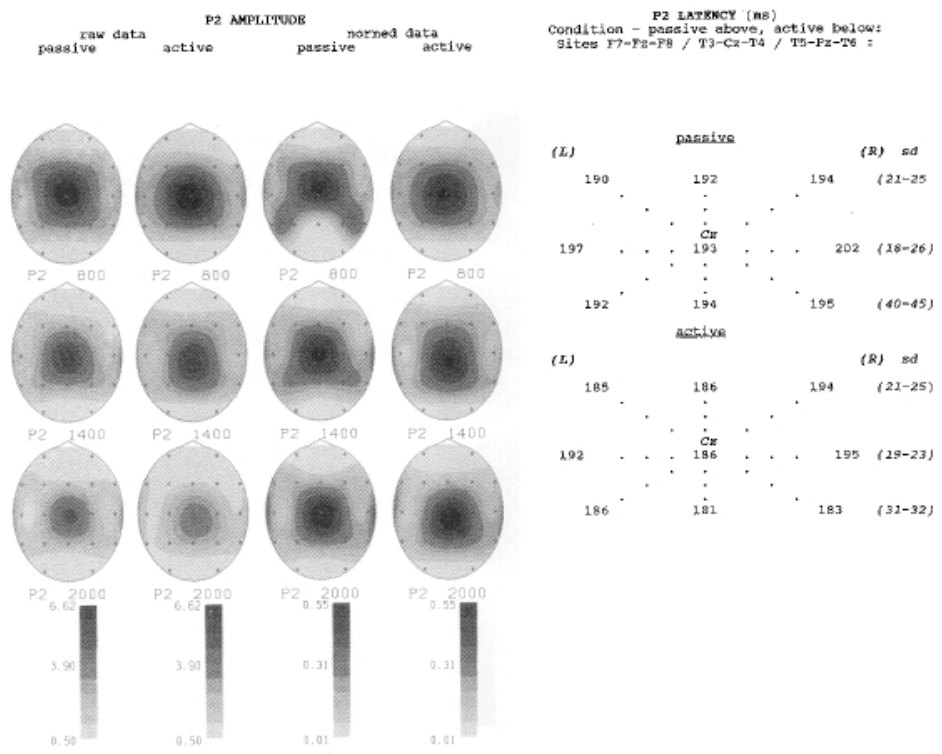

FIGURE 4 See Fig. 2. (Left) A reducing effect of P2 amplitude with pitch is seen in raw not normalized data. Peaks centred over centroparietal regions in the midline. Frontal positivity was more cvident over the left hemisphere. (Right) Latencies tended to be shorter in the active condition (especially over left frontal regions).

N2

Amplitude. There were no significant effects at $\mathrm{Cz}$. N2 peaks were more negative at all frontal vs posterior sites for all tones $(\mathrm{t}-2.7$ to $-7.2, p=.000)$. There were no lateral differences.

Common tones tended to elicit less negative peaks than rare ones at left (T3, P3; Scheffe $p<.05)$ and right anterior temporal sites (T4; $p<.01$, T2 not averaged tests after e-correction, Fig. 5).

Latency. At $\mathrm{Cz}$ latencies were shorter in the active condition and shorter to the rare tones $(\mathrm{c} .8 \% ; \mathrm{F}(1,132)=7.1, p=.009 ; \mathrm{F}(2,132)=4.4, p=.014$, respectively). Surprisingly $\mathrm{N} 2$ peaked later at frontal vs posterior sites (despite peaks being larger frontally). This was clearest for standard tones $(2.0 \& 0.8 \mathrm{KHz}, \mathrm{Fz} / \mathrm{Pz}, \mathrm{t} 2.5$ to $3.5, p=.02-0.001)$.

Latencies tended to be longer after rare tones at T6 in contrast to their being shorter than after the common tone elsewhere (e.g., F7; both effects Scheffe $p<.05$, although T2 but not e-corrected averaged tests were significant).

P3

Amplitude. At Cz both rare tones elicited larger responses than the common standard and the peaks were larger in the attention condition $(\mathrm{F}(2,132)=15.9, p=.000, \mathrm{~F}(1,132)=27.9$, $p=.000$ respectively). Peaks were about twice as large at posterior than at anterior sites in 

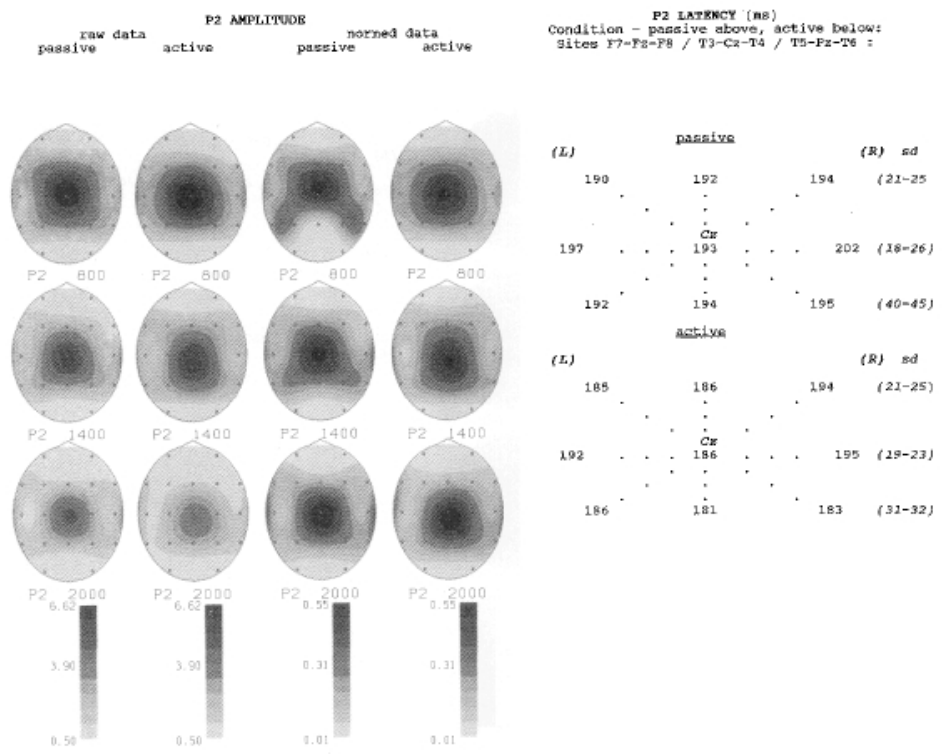

FIGURE 4 See Fig. 2. (Left) A reducing effect of P2 amplitude with pitch is seen in raw not normalized data. Peaks centred over centroparietal regions in the midline. Frontal positivity was more cvident over the left hemisphere. (Right) Latencies tended to be shorter in the active condition (especially over left frontal regions).

N2

Amplitude. There were no significant effects at $\mathrm{Cz}$. N2 peaks were more negative at all frontal vs posterior sites for all tones $(\mathrm{t}-2.7$ to $-7.2, p=.000)$. There were no lateral differences.

Common tones tended to elicit less negative peaks than rare ones at left (T3, P3; Scheffe $p<.05)$ and right anterior temporal sites (T4; $p<.01$, T2 not averaged tests after e-correction, Fig. 5).

Latency. At $\mathrm{Cz}$ latencies were shorter in the active condition and shorter to the rare tones $(\mathrm{c} .8 \% ; \mathrm{F}(1,132)=7.1, p=.009 ; \mathrm{F}(2,132)=4.4, p=.014$, respectively). Surprisingly $\mathrm{N} 2$ peaked later at frontal vs posterior sites (despite peaks being larger frontally). This was clearest for standard tones $(2.0 \& 0.8 \mathrm{KHz}, \mathrm{Fz} / \mathrm{Pz}, \mathrm{t} 2.5$ to $3.5, p=.02-0.001)$.

Latencies tended to be longer after rare tones at T6 in contrast to their being shorter than after the common tone elsewhere (e.g., F7; both effects Scheffe $p<.05$, although T2 but not e-corrected averaged tests were significant).

P3

Amplitude. At Cz both rare tones elicited larger responses than the common standard and the peaks were larger in the attention condition $(\mathrm{F}(2,132)=15.9, p=.000, \mathrm{~F}(1,132)=27.9$, $p=.000$ respectively). Peaks were about twice as large at posterior than at anterior sites in 


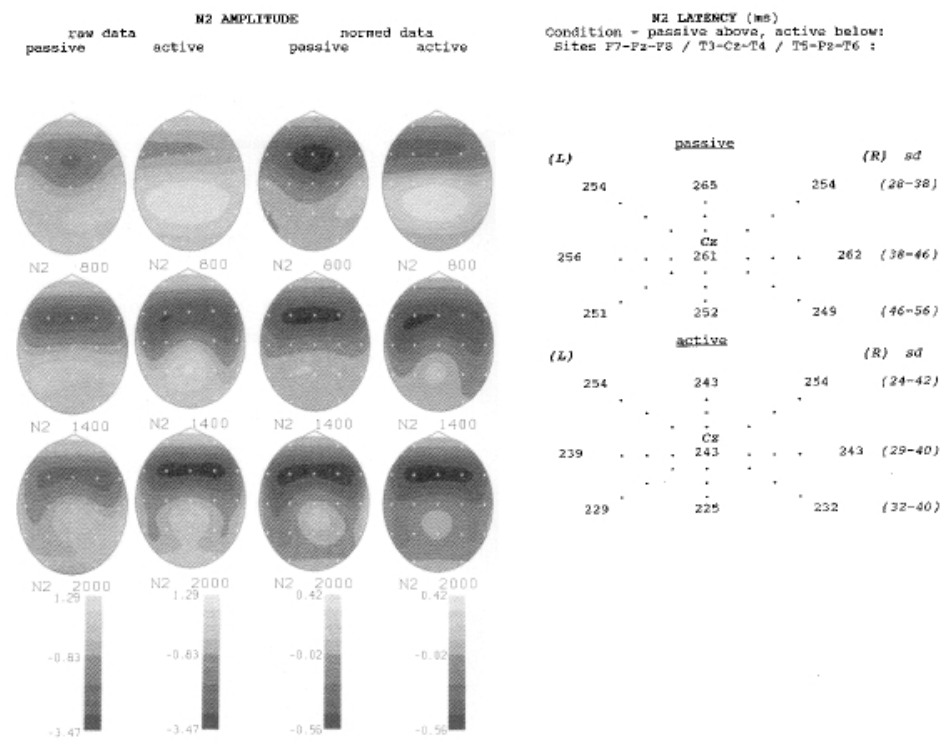

FIGURE 5 See Fig. 2. (Left) N2 peaks showed frontal maxima. In contrast to the raw data, after normalization equivalent responses to each tone were seen in the passive condition but in the active condition the common tone response is reduced. (Right) Rare tone responses occurred sooner, particularly in the active condition, but not at temporal sites.

both conditions ( $\mathrm{t}-5.6$ to $-9.9, p<.000$ ). In the passive condition amplitudes were larger at T6 than T5 ( $\mathrm{t}-2.33, p=.02$; Fig. 6$)$.

Both tone and condition by site interactions were significant. P3 amplitude at T6 was larger after the common than after the deviant standard (Scheffe $p<.05$ ) but the condition dependent increase was not evident at T4 and T6 $(\mathrm{F}(1,136)=5.3-10.5, p=.02-.002)$.

Latency. There were no main effects of tone, condition or site. Tone or condition $\mathrm{x}$ site interactions could not be consistently confirmed (averaged tests but not T2-test significant) but the trend encouraged us to look further for a P3a vs P3b separation. While P3 after the deviant tended to occur earlier at frontal sites (i.e., $\mathrm{P} 3 \mathrm{a}$ : $\mathrm{Fz} / \mathrm{F} 8$ vs $\mathrm{Pz} / \mathrm{T} 6, \mathrm{t}=-1.8$ to $2.0, p$ $=.05-.08), \mathrm{P} 3$ after the common standard tended to occur later frontally $(\mathrm{Fz} / \mathrm{F} 7 \mathrm{vs} \mathrm{Pz} / \mathrm{T} 5$, $\mathrm{t}=2.8-3.7, p=.001-.008)$. Indeed the latency after the common was longer than after the deviant standard at $\mathrm{Fz}$ (Scheffe $p<.05$ ). Thus $\mathrm{P} 3$ a proved poorly differentiated in this paradigm (Fig. 6).

\section{DISCUSSION}

\section{General}

Interactions of site with the variable of interest, with normalized data, are necessary for drawing conclusions about the likelihood of different neural sources for ERP components 
raw data
passive active
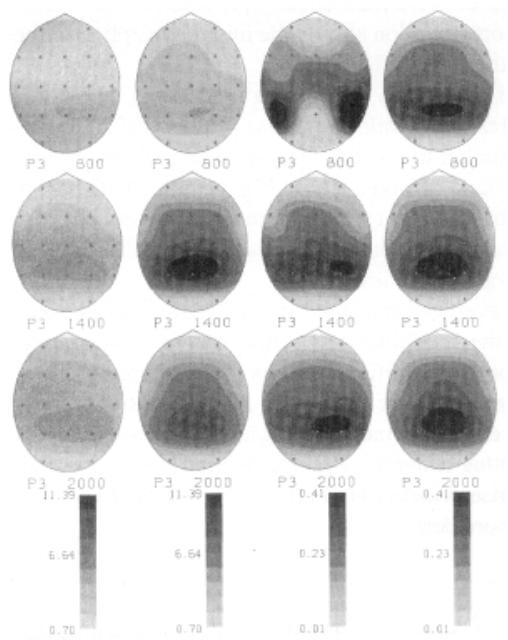

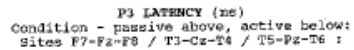

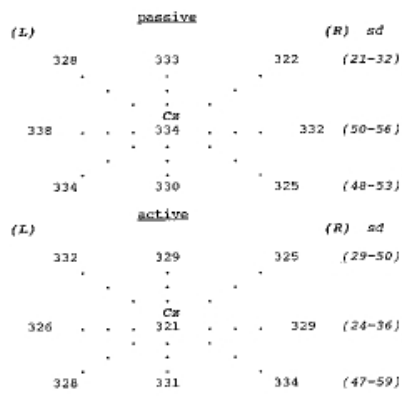

FIGURE 6 See Fig. 2. (Left) Larger P3 responses were recorded posteriorly; normalization showed this for all tones, also that 1) responses were larger on the right in the passive condition, and 2) large responses seen in both conditions differed between tones in the spread rather than the degree of positivity shown. (Right) Variable measures precluded showing antero-posterior latency differences varying with tone or condition.

(Johnson, 1993). Significant interactions of site with tone for amplitude were found as early as the P1 and also for $\mathrm{N} 2$ and P3. Interactions of site with attentional condition were not recorded until the $\mathrm{P} 3$ component. For latency the first interactions with tone occurred with $\mathrm{P} 2$ and subsequently with $\mathrm{P} 3$, whereas for condition they concerned P3. Of interest is 1) the near lack of interaction for the N1-P2 complex, 2) the early and late influence of tone and 3 ) the influence of attentional condition only from the N2-P3 complex.

\section{Methods}

The task and stimulus parameters proved appropriate where the aim was to study early and late components and eventually to apply the paradigm to psychiatric patients (e.g., all healthy adults and 30/33 schizophrenics were able to perform the discrimination, in prep.).

The main methodological interest lies with the procedure for normalization and the use of Hotellings T2 test as a permissive filter for accepting the results of the "averaged" tests across electrodes. Three main normalization methods have been discussed for ERP data (McCarthy \& Wood, 1985; Naumann et al., 1992). These authors have illustrated the weakness of the percentage method. While the "max-min" method has been relatively widely applied (e.g., Oades et al., 1990), some anomalous transformations were encountered that proved difficult to interpret and were not evident after vector normalization. Although re- 
ports of the vector method have been published by relatively few laboratories (e.g., Shelley et al., 1991; O'Donnell et al., 1993), it is favored as more statistically sound as variance is included from all recording sites. While this is appropriate for healthy subjects, major localized dysfunction in brain-damaged patients could theoretically provide unwanted bias with this method. (Some instances where normalization altered the initial perception of the raw data are mentioned in the results, discussion and figures.)

It is important to correct for the number of degrees of freedom in analyses where few subjects provide a large number of measures (e.g. epsilon), but use of the most conservative approach of arbitrarily reducing the number to one has caused some authors to comment on the sparsity of significant effects found (Woods, 1992). If psychiatric patients are studied, with the inevitable increased variability of data arising from small numbers of subjects in variable clinical states, then the use of this method will result in the likelihood of finding meaningful differences falling beyond useful levels.

Use of the conventional e-correction for averaged tests brought the results into the same order of magnitude as that resulting from the Hotellings test. The combined use of these tests provided the criterion for separating out the significant results meriting conservative, posthoc verification (Scheffe). Exploration of posthoc tests after conflicts between averaged and Hotellings tests did not uncover a consistent pattern of significant/non-significant results. This illustrates the danger of accepting either test alone as a criterion for proceeding in the analysis. We now briefly summarise evidence about the sources of the ERP components before considering the results in more detail.

\section{Background on ERP Sources}

Upto $30 \mathrm{~ms}$ post-stimulus potentials reflect brainstem and midbrain relays (Buchwald et al., 1981; Hashimoto, 1982). Later ERPs reflect the processing of information in the cortex or that has passed through the cortex. But although the P50/P1 component has a generator in primary auditory cortex (planum temporale: Smith \& Kraus, 1988; Reite et al., 1988), there may be conditions where the component reflects firing in the thalamus (Erwin \& Buchwald, 1986).

Electrical dipole and magnetic studies show several tonotopic sources for N1 in the primary auditory cortex (Scherg et al., 1989) lateral to the sylvian fissure (Arthur et al., 1991) and $\mathbf{P} 2$ in secondery auditory cortex in the more lateral temporal gyri (Vaughan \& Arezzo, 1988; Makela \& Hari, 1990). Reports on N2 sources concentrate on difference-waves (see following report). It may be linked with $\mathrm{P} 3$ and recorded widely from frontal to more lateral temporal positions (Smith et al., 1990) and may, unlike P3a, even be absent when attention is not required (Paavilainen et al., 1991).

The source of the centroparietal P3 varies with modality (Pineda \& Westerfield, 1993) and task requirements (Falkenstein et al., 1993). It may reflect auditory cortical activity in inferior parietal regions, but not deeper P3 sources (e.g., hippocampus, Smith et al., 1990; Attias \& Pratt, 1991: thalamus, Rogers et al., 1991). Separate sources may contribute to frontal and temporal $\mathrm{P} 3 \mathrm{~s}$, but the functional relations of these remain a matter for discussion (Halgren, 1988; Smith et al., 1990; Curran et al., 1993).

\section{ERP Components (present results)}

P1 peaked earlier on the left and over frontal regions. Normalized amplitudes showed similar distributions to the raw data but the quantity and extent of positivity was restricted. All tones elicited to varying degrees a left-biased frontocentral peak, but there were also pos- 
itive shifts on the right over frontal (common tone), anterotemporal (target) and posterotemporal regions (deviant). A posterior shift with increasing pitch was also noted by Woods and Alain (1993). Such tone-specific and non-specific groupings recall the demonstration of separate pathways (lemniscal with/without extralemniscal contributions) to lateral and midline cortices in the rat (Simpson \& Knight, 1993). A further feature of interest is the breadth of the frontal response to the common tone, especially in the passive condition. Perhaps this reflects the registration of a reference trace for comparison with other tones potentially of more interest (e.g., through rarity, see Näätänen, 1990). An influence of attention condition on P1 (Hackley et al., 1987) was not confirmed, but the paradigm was unsuited for this purpose.

Like Pl, the N1 peaks earlier on the left and over frontal areas. The frontocentral maximum is well-known but the bias towards left frontal and temporal hemispheres less so. But several groups have recently reported supratemporal generators with other methods (e.g. Tiitinen et al., 1993). The absence of interactions was surprising in view of reports of tonotopic generator differences (Tiitinen et al., 1993) and effects of attention condition on N1 amplitude (Hink et al., 1978).

P2 also tended to show shorter latencies on the left and over frontal areas (particularly in the active condition) which contrasts with the peak maxima found more posteriorly over centro-parietal areas. At these sites there was a "reducing" effect on P2 amplitude with increasing pitch (raw data), which was not evident in the topographic distribution (normalized data, Fig. 4). This is of interest in view of the subjective difference of intensity associated with stimuli of increasing pitch and the claim that $\mathrm{P} 2$ may reflect inhibitory processes acting on intense stimuli (Hegerl \& Juckel, 1993).

With the onset of $\mathrm{N} 2$ interactions start to appear. Tone rarity is a criterion for peaks to arrive early and to show the largest maxima frontally. This is emphasized by the decreased prominence after the common tone when attention becomes focussed, even though this does not show up as a 3-way interaction (Fig. 5). The functional association of N2 with stimulus rarity is borne out by studies of difference waves (see accompanying article) and is here anticipated by the relative positivity of the $\mathrm{N} 2$ after the common tone. These data support claims that N2 is sensitive to stimulus probability (Wijers et al., 1987) and discrimination difficulty (Ritter et al., 1979). The posterior spread of negativity visible in the active condition at T6 (normalized data) obtains significance in conjunction with the P3 (below) and, speculatively, may relate to parahippocampal activity. Unlike previous peaks there were no lateral asymmetries.

It is well-known that features of stimulus rarity as well as goal (e.g., deviant-P3a, targetP3b) can elicit a large positive shift. But here this is only appreciable from normalized data at far lateral frontal sites (Fig. 6). There was some statistical evidence for separating P3a from $\mathbf{P} 3 b$, (e.g., shorter latency at frontal sites especially after the deviant), but we were surprised that a distinction between a frontal P3a and a parietal P3b was not more overt.

Two lateralized effects are of interest. 1) Passive P3 amplitudes were larger at right posterior temporal sites (especially for the common tone), but focussing attention brought the maxima into the midline. Together with the $\mathrm{N} 2$ association with rare stimuli (above) this emphasizes the stimulus- rather than target-related nature of the response over temporal sites. 2) Despite the increase of amplitude posteriorly with focussed attention, this shift was relatively absent over right temporal areas (T4 \& T6). This is of interest as an impairment in the passive/active shift at left temporal sites was reported in schizophrenics (Faux et al., 1988). Our data imply a role for effort in focussed attention evident in $P 3$ at left not right posterior sites, that may be impaired in psychosis. 


\section{Conclusions}

The type of tone or mode of attention in a 3-tone oddball shows up topographic differences for a range of components and provides a basis for the search for correlates of psychiatric impairments. This contrasts with the 2 -tone oddball which, though easy to perform, provides less differentiated and non-specific results and differs from other dichotic tasks widely used in normal psychology that are difficult for psychiatric patients. A disadvantage is that the results were relatively undifferentiated around the N1 component. But this is offset by the advantages of studying a range of subtraction waves as is shown in the accompanying report.

\section{REFERENCES}

Arthur, D. L., Lewis, P. S., Medvick, P. A. \& Flynn, E. R. (1991). A neuromagnetic study of selective auditory attention. Electroencephalography and Clinical Neurophysiology, 78. 348-360.

Attias, J. \& Pratt, H. (1991). Applications of three-dimensional analysis to the auditory P300. International Joumal of Neuroscience, $58,95-103$.

Breton, F., Ritter, W., Simson, R. \& Vaughan, H. G. (1988). The N2 component elicited by stimulus matches and multiple targets. Biological Psychology, 27, 23-44.

Buchwald, J. S., Hinman, C., Norman, R. J., Huang, C. M. \& Brown, K. A. (1981). Middle and long-latency auditory evoked responses recorded from the vertex of normal and chronically lesioned cats. Brain Research, $205,91-109$

Curran, T., Tucker, D. M., Kutas, M. \& Posner, M. I. (1993). Topography of the N400: brain electrical activity reflecting semantic expectancy. Electroencephalography and clinical Neurophysiology, 88, 188-210.

Donchin, E \& Coles, M. G. H. (1988). Is the P300 component a manifestation of context updating? Behavioral Brain Sciences, 11, 357 427.

Erwin, R. J. \& Buchwald, J. S. (1986). Midlatency auditory evoked response: differential effects of sleep in the human. Electroencephalography and Clinical Neurophysiology, 65, 383-392.

Falkenstein, M., Hohnsbein, J. \& Hoornamm, J. (1993). Late visual and auditory ERP components and choice reaction time. Biological Psychology, 35, 201-224.

Faux, S. F. \& McCarley, R. W. (1990). Analysis of scalp voltage asymmetries asing Hotelling's T2 methodology. Brain Topography, 2, 237-245.

Faux, S. F., Shenton, M. E., McCarley, R. W., Torello, M. W. \& Duffy, F. H. (1988). Differentiation of schizophrenics and normal controls is enhanced by the Goodin subtraction procedure. International Journal of Neuroscience, $38,117-135$.

Ford, J. M., Pfefferbaum, A. \& Roth, W. (1992). P3 and schizophrenia. Annals of the New York Academy of Sciences, 658, 146-162.

Greenhouse, S. W. \& Geisser, S. (1959). On methods in the analysis of profile data. Psychometrika, 24, 95-112.

Grillon, C., Courchesne, E., Ameli, R., Elmasian, R. \& Braff, D. (1990). Effects of rare non-target stimuli on brain electrophysiological activity and performance. International Joumal of Psychophysiology, 9, 257-267.

Hackley, S. A., Woldorff, M. \& Hillyard, S. A. (i 987). Combined use of microreflexes and event-related brain potentials as measures of auditory selective attention. Psychophysiology, 24, 632-647.

Halgren, E. (1988). The P3; a view from the brain. Behavioral Brain Sciences, 11, 383-385.

Hashimoto, 1. (1982). Auditory evoked potentials from the human midbrain: slow brain stem responses. Electroencephalography and Clinical Neurophysiology, 53, 652-657.

Hegerl, U. \& Jucke], G. (1993). Intensity dependence of auditory evoked potentials as an indicator of central serotonergic neurotransmission: a new hypothesis. Biological Psychiatry. 33, 173-187.

Hink, R. F., Fenton, W. H., Pfefferbaum, A., Tinklenburg, J. R. \& Kopell, B. S. (1978). The distribution of attention across auditory input channels: an assessment using the human auditory evoked potential. Psychophysiology, 15, 466-473.

Iragui, V. J., Kutas, M.. Mitchiner, M. R. \& Hillyard, S. A. (1993). Effects of aging on event-related potentials and reaction times in an auditory oddball task. Psychophysiology, 30, 10-22.

Johnson, R. (1993). On the neural generators of the P300 component of the event-related potential. Psychophysiotogy, 30, 90-97.

Keselman, H. J. \& Rogan, J. C. (1980). Repeated measures F tests and psychophysiological resarch: controlling the number of false positives. Psychophysiology, 17, 499-503.

Makela, J. P. \& Hari, R. (1990). Long-latency auditory evoked magnetic fields. Advances in Neurology, 54, $177-191$.

McCarthy, G. \& Wood, C. C. (1985). Scalp distribution of event-related potentials: an ambiguity associated with analysis of variance models. Electroencephalography and Clinical Neurophysiology, 62, 203-208. 
Näätänen, R. (1990). The role of attention in auditory information processing as revealed by event-related potentials and other brain measures of cognitive function. Behavioral Brain Sciences, 13, $201-288$.

Näätänen, R., Sams, M., Alho, K., Reinikainen, K. \& Sokolov, E. N. (1988). Frequency and location specificity of the human vertex N1 wave. Electroencephalography and Clinical Neurophysiology, 69, 523-531.

Naumann, E., Huber, C., Maier, S., Plihal, W., Wustmans, A., Diedrich, O. \& Bartussek, D. (1992). The scalp topography of P300 in the visual and auditory modalities: a comparison of three normalization methods and the control of statistical type II error. Electroencephalography and Clinical Neurophysiology, 83, 254-264.

Novak, G. P., Ritter, W., Vaughan, H. G. \& Wiznitzer, M. L. (1990). Differentiation of negative event-related potentials in an auditory discrimination task. Electroencephalography and Clinical Neurophysiology, 75 , $255-275$.

Oades, R. D., Walker, M. K., Geffen, L. B. \& Stern, L. M. (1988). Event-related potentials in autistic and healthy children on an auditory choice reaction time task. International Joumal Psychophysiology, 6, 25-37.

Oades, R. D., Stern, L. M., Walker, M. K., Clark, C. R. \& Kapoor, V. (1990). Event-related potentials and monoamines in autistic children on a clinical trial of fenfluramine. International Journal of Psychophysiology, 8, 197-212.

O'Donnell, B. F., Friedman, S., Squires, N. K., Maloon, A., Drachman, D. A. \& Swearer, J. M. (1990). Activeand passive P3 latency in dementia: relationship to psychometric, electroencephalographic and computed tomographic measures. Neuropsychiatry, Neuropsychology and Behavioral Neurology, 3, 164-179.

O'Donnell, B. F., Shenton, M. E., McCarley, R. W., Faux, S. F., Smith, R. S., Salisbury, D. F., Nestor, P. G., Pollak, S. D., Kikinis, R. \& Jolesz, F. A. (1993). The auditory N2 component in schizophrenia: relationship to MRI temporal lobe gray matter and to other ERP abnomalities. Biological Psychiatry, 34, 26-40.

Paavilainen, P., Alho, K., Reinikainen, K., Sams, M. \& Näätänen, R. (1991). Right hemisphere dominance of different mismatch activities. Electroencephalography and Clinical Neurophysiology, 78, 466-479.

Pfefferbaum, A., Ford, J. M., Wenegrat, B. G., Roth, W. T. \& Kopell, B. S. (1984). Clinical application of the P3 component of event-related potentials. 1. Normal aging. Electroencephalography and Clinical Neurophysiology, 59, 85-103.

Pineda, J. A. \& Westerfield, M. (1993). Monkey P3 in an "oddball" paradigm: pharmacological support for multiple neural sources. Brain Research Bulletin, 31, 689-696.

Pivik, R. T., Broughton, R. J., Coppola, R., Davidson, R. J., Fox, N. \& Nuwer, M. R. (1993). Guidelines for the recording and quantitative analysis of electroencephalographic activity in research contexts. Psychophysiology, 30, 547-558.

Polich, J. (1987). Comparison of $\mathrm{P} 300$ from a passive tone sequence paradigm and an active discrimination task. Psychophysiology, 24, 41-46.

Polich. J. (1991a). P300 in the evaluation of aging and dementia. Electroencephaiography and clinical Neurophysiology, suppl. 42, 304-323.

Polich, J. (1991b). P300 in clinical applications: meaning, method and measurement. American Journal of Electroencephalographic Technology, 3I, 20l-23I.

Reite, M., Teale, P., Zimmerman, J., Davis, K., Whalen, J. \& Edrich, J. (1988). Source origin of a 50 msec latency auditory evoked field component in yourng schizophrenic men. Biological Psychiatry, 24, 495-506.

Ritter, W., Simson, R., Waughan, H. G. \& Friedman, D. (1979). A brain event related to the making of a sensory discrimination. Science, 203, 1358-1361.

Rogers, R. L., Baumann, S. B., Papanicolau, A. C., Bourbon, T. W., Alagarsamy, S. \& Eisenberg, H. M. (1991). Localization of the P3 sources using magnetencephalography and magnetic resonance imaging. Electroencephalography and clinical Neurophysiology, 79, 308-321.

Rugg, M. D., Pickles, C. D., Potter, D. D., Doyle, M. C., Pentland, B. \& Roberts, R. C. (1993). Cognitive brain potentials in a three-stimulus auditory "oddball" task afterclosed head injury. Neuropsychology, 31, 373-393.

Scherg, M., Vajsar, J. \& Picton, T. W. (1989). A source analysis of the human auditory evoked potential. Journal of cognitive Neuroscience, $1,336-355$.

Shelley, A. M., Ward, P. B., Michie, P. T., Andrews, S., Mitchell, P. F., Catts, S. V. \& McConaghy, M. (1991). The effect of repeated testing on ERP components during auditory selectve attention. Psychophysiology, 28, 496-510.

Simpson, G. V. \& Knight, R. T. (1993). Multiple brain systems generating the rat auditory evoked potential. II. Dissociation of auditory cortex and non-lemniscal generator systems. Brain Research, 602, 251-263.

Smith, D. I. \& Kraus, N. (1988). Intracranial and extracranial recordings of the auditory middle latency response. Electroencephalography and clinical Neurophysiology, 71, 296-303.

Smith, M. E., Halgren. E., Sokolik. M., Baudena, P., Musolino, A., Liegeois-Chauvel, C. \& Chauvel, P. (1990). The intracranial topography of the $\mathrm{P} 3$ event-related potential during auditory oddball. Electroencephalography and clinical Neurophysiology, 76, 235-248.

Squires, N. K., Squires, K. C. \& Hillyard, S. A. (1975). Two varieties of long latency positive waves evoked by unpredictable auditory stimuli in man. Electroencephalography and Clinical Neurophysiology, 38, 387-401.

Tachibana, H., Toda, K. \& Sugita, M. (1992). Age-related changes in attended and unattended P3 latency in normal subjects. Intemational Journal of Neuroscience, 66, 277-284.

Teder, W., Alho, K., Reinikainen, K. \& Năătänen, R. (1993). Interstimulus interval and the selective attention effect on auditory ERPs: "N1 enhancement" versus processing negativity. Psychophysiology, 30, 71-81. 
Tiitinen, H., Alho, K., Huotilainen, M., Ilmoniemi, R. J., Simola, J. \& Näätänen, R. (1993). Tonotopic auditory cortex and the magnetoencephalographic (MEG) equivalent of the mismatch negativity. Psychophysiology, 30, 537-540.

Vasey, M. W. \& Thayer, J. F. (1987). The continuing problem of false positives in repeated measures ANOVA in psychophysiology: a multivariate solution. Psychophysiology, 24, 479-486.

Vaughan, H. G. \& Arezzo, J. C. (1988). The neural basis of event-related potential. In T. W. Picton (Ed.), Human event-related potentials. (pp. 45-96) Amsterdam: Elsevier.

Verleger, R. (1988). Event-related potentials and cognition: a critique of the context updating hypothesis and an alternative interpretation of P3. Behavioral Brain Science, 11, 343-427.

Wijers, A. A., Okita, T., Mulder, G., Mulder, L. J. M., Lorist, M. M., Poiesz, R. \& Scheffers, M. K. (1987). Visual search and spatial attention: ERPs in focussed and divided attention conditions. Biological Psychology, 25, $33-60$.

Woods, D. L. (1992). Auditory selective attention in middle-aged and elderly subjects: an event-related brain potential study. Electroencephalography and Clinical Neurophysiology, 84, 456-468.

Woods, D. L. \& Alain, C. (1993). Feature processing during high-rate auditory selective attention. Perception and Psychophysics, 53, 391-402.

Appendix of analysis of variance results for amplitude and latency of 5 ERP components in the passive-active 3-tone oddball task; 1) averaged tests with Greenhouse-Geisser df-correction, 2)

Hotelling's T2 test.

\begin{tabular}{|c|c|c|}
\hline Component measures and factors: & Site-averaged tests & Hotellings $\mathrm{T} 2$ test \\
\hline \multicolumn{3}{|l|}{ P1 } \\
\hline \multicolumn{3}{|l|}{ amplitude: $e=.372$} \\
\hline $\begin{array}{l}\text { site, } \\
\text { tone } \times \text { site, }\end{array}$ & $\begin{array}{l}F(5,687)=5.4, p=.000 \\
\mathrm{~F}(10,687)=2.0, p=.002\end{array}$ & $\begin{array}{l}12 \mathrm{~F}(14,119)=4.2, p=.000 \\
\mathrm{~T} 2 \mathrm{~F}(28,236)=1.4, p=.08:\end{array}$ \\
\hline \multicolumn{3}{|l|}{ latency: $e=.311$} \\
\hline & $\mathrm{F}(4,575)=2.7, p<.001$ & $\mathrm{~T} 2 \mathrm{~F}(14,119)=4.7, p=.000$ \\
\hline \multicolumn{3}{|l|}{$\begin{array}{l}\text { N1 } \\
\text { amplitude: } e=.286 \text {, }\end{array}$} \\
\hline latency: $e=.403$ & & \\
\hline $\begin{array}{l}\text { site, } \\
\text { P2 }\end{array}$ & $\mathrm{F}(6,745)=24.5, p=.000$ & $\mathrm{~T} 2 \mathrm{~F}(14,119)=29.0, p=.000$ \\
\hline amplitude: $e=.264$, & & \\
\hline $\begin{array}{l}\text { site, } \\
\text { tone } \times \text { site, }\end{array}$ & $\begin{array}{l}F(4,488)=36.9, p=.000 \\
F(7,488)=1.4, p=.072\end{array}$ & $\begin{array}{l}\mathrm{T} 2 \mathrm{~F}(14,119)=28.9, p=.000 \\
\mathrm{~T} 2 \mathrm{~F}(28,236)=2.3, p=.001:\end{array}$ \\
\hline \multicolumn{3}{|l|}{ latency: $e=.311$} \\
\hline site, & $\mathrm{F}(4,575)=2.7, p=.000$ & $\begin{array}{l}\mathrm{T} 2 \mathrm{~F}(14,119)=4.7, p=000 ; \\
\mathrm{T} 2 \mathrm{~F}(28236)=1\end{array}$ \\
\hline \multicolumn{3}{|l|}{$\begin{array}{l}\mathrm{N} 2 \\
\text { amplitude: } e=.293 \text {, }\end{array}$} \\
\hline site. & $\mathrm{F}(4,541)=41.8, p=.000$ & $\mathrm{~T} 2 \mathrm{~F}(14,119)=25.7, p=.000$ \\
\hline $\begin{array}{l}\text { tone } \times \text { site, } \\
\text { latency: } e=.429,\end{array}$ & latency: $e=.429$ & $\mathrm{~T} 2 \mathrm{~F}(28,236)=2.4, p=.000$ \\
\hline site, & $\mathrm{F}(6,793)=4.7, p=.000$ & $\mathrm{~T} 2 \mathrm{~F}(14,119)=2.1, p=.018$ \\
\hline $\begin{array}{l}\text { tone } \times \text { site, } \\
\text { P3 }\end{array}$ & $\mathrm{F}(6,793)=1.6, p=.024^{*}$ & $\mathrm{~T} 2 \mathrm{~F}(28,236)=1.6, p=.03^{*}:$ \\
\hline \multicolumn{3}{|l|}{ amplitude: $e=.319$} \\
\hline site, & $\mathrm{F}(4,589)=58.4, p=.000$ & $\mathrm{~T} 2 \mathrm{~F}(14,119)=18.1, p=.000 ;$ \\
\hline tone $\times$ site & $\mathrm{F}(9,589)=2.2, p=.000$ & $\mathrm{~T} 2 \mathrm{~F}(14.119)=3.0 . p=.000$ \\
\hline $\begin{array}{l}\text { condn } \times \text { site, } \\
\text { latency: } e=.396\end{array}$ & $\mathrm{~F}(4,589)=3.9, p=.000$ & $\mathrm{~T} 2 \mathrm{~F}(14,119)=3.0, p=.000$ \\
\hline tone $\times$ site, & $\mathrm{F}(11,732)=2.5, p=.000$ & $\mathrm{~T} 2 \mathrm{~F}(28.236)=1.3, p=.17$ \\
\hline condn $\times$ site, & $F(5,732)=2.3, p=.005$ & $\mathrm{~T} 2 \mathrm{~F}(14,119)=1.8, p=.04^{*}:$ \\
\hline
\end{tabular}

Notes: Rexults are cited if averaged or Hoteilings test gave a clear or borderline significant result: the degrees of frecdon (dt) cited for the averaged tests are corrected by the epsilon (e) value: * = not signiticant after Greenhouse-Geisser correction. 